\title{
O CÉREBRO COMO ÓRGÃO PESSOAL: UMA ANTROPOLOGIA DE DISCURSOS NEUROCIENTÍFICOS
}

THE BRAIN AS A PERSONAL ORGAN: AN ANTHROPOLOGY OF NEUROSCIENTIFIC DISCOURSES

Rogerio Lopes Azize ${ }^{1}$

Resumo Trata-se de discutir em que sentido o discurso neurocientífico sobre o cérebro produz uma determinada noção de pessoa. Em especial, invisto em autores e textos que fazem divulgação científica. A ideia do 'cérebro como pessoa' é repetida em formatos variados em livros de divulgação de importantes neurocientistas, que visam atingir os seus pares especialistas, assim como constituir e ampliar o número de novos curiosos a respeito do funcionamento do cérebro. Postulo, como contribuição ao debate, a ideia de que um 'cerebralismo' - uma concepção fisicalista de pessoa que relaciona cérebro e indivíduo - constitui um traço central na concepção de pessoa moderna.

Palavras-chave pessoa; cérebro; neurociência; divulgação científica.
Abstract The goal is to discuss in what regard the discourse of neuroscience about the brain produces a particular notion of personhood. In particular, I investigate authors and texts that disseminate science. The idea of the 'brain as a person' is repeated in several formats in books written by renowned neuroscientists designed to reach their specialist pairs, as well as to establish and expand the number of people who become intrigued about how the brain works. I postulate, to contribute to the debate, the idea that a 'cerebralism' - a physicalist conception of person that relates the brain and the individual - is a central feature in the notion of the modern person.

Keywords person; brain; neuroscience; scientific divulging. 
Uma hierarquia tem se solidificado nas apresentações científicas a respeito dos órgãos do corpo humano. Cada vez mais o cérebro, cuja possibilidade de transplante ainda soa como ficção científica, é visto como o 'órgão pessoal' por excelência, aquele que de fato define e carrega identidades individuais, em comparação a outros que seriam essenciais para a vida humana, mas transplantáveis e intercambiáveis. É comum encontrar variações dessa concepção naturalista e cerebral de pessoa em textos de neurociência - não apenas naqueles de circulação interpares, publicados em periódicos científicos especializados, ou mesmo livros-texto para estudantes, mas também em material que se propõe a se comunicar com um público não iniciado nos ramos da ciência que se ocupam do cérebro. Minha contribuição para esta seção Debate consiste em uma análise de material deste último tipo, que tem como objetivo declarado atingir também um público leigo, adaptando tanto a forma quanto o conteúdo da mensagem para esse fim. Foi mergulhando nas produções de neurocientistas voltadas para um público amplo que encontrei repetidas evidências dessa noção, hoje muito em voga, do 'cérebro como órgão pessoal' e do 'cérebro como pessoa'.

Nessa particular concepção de pessoa, receba-se um coração, rim, fígado ou córneas que já foram parte de outro corpo, e não pairam dúvidas de que o receptor continua a ser quem ele é. Mas o cérebro é um órgão limite para a concepção ocidental moderna de pessoa, um "limite somático" (Ferret, 1993, p. 12, 99) além do qual cessamos de ser nós mesmos, seja para definir a identidade pessoal em vida, seja para definir os limites entre vida e morte. O cérebro - não a cabeça, nem a 'mente' ou a 'alma', mas o órgão físico ele mesmo -, nesse contexto cultural, é muitas vezes sinônimo de indivíduo.

Não se trata de novidade a atribuição de uma importância central, de emoções ou de características morais a este ou àquele órgão do corpo humano. O coração ainda hoje tem um lugar de destaque no imaginário ocidental e por vezes surge em contraste com o cérebro representando, nesta ordem, um órgão relacionado às emoções e outro à razão. Mesmo um 'cerebrocentrismo' não é uma invenção recente, remetendo, em uma primeira parada, a esforços de localização cerebral (de ordem física e moral) que tiveram grande aceitação nos séculos XVIII e XIX, mesmo entre o público leigo, ainda que, em algumas de suas versões, tenham caído em descrédito posteriormente.

O cérebro, por assim dizer, ganhou vida própria, um órgão ao qual se faz referência na terceira pessoa. Ora, alguém poderia argumentar que é assim também que nos referimos aos nossos rins. Mas não atribuímos aos rins a sede da nossa personalidade, como hoje se atribuí ao cérebro (Greenfield, 1997), tampouco o controle da nossa racionalidade e das nossas emoções, de nossos reflexos e crenças, da criatividade, da memória e da inteligência. Nós não somos os nossos rins ou o nosso fígado, ainda que qualquer afecção, em qualquer órgão humano, possa estar cercada de questões de ordem moral, 
e não somente física. Talvez apenas o coração tenha força simbólica equivalente, contrapondo-se ao cérebro em termos, nesta ordem, de emoção e razão, mas também esta divisão tende a enfraquecer quando se apresenta o cérebro como lugar de onde emanam emoções e sentimentos.

Por sua vez, é bastante evidente no que diz respeito ao cérebro uma dinâmica que permite tomar a parte pelo todo - ao menos esta é a ideia que vemos se repetir no discurso da neurociência contemporânea e mesmo em saberes sobre o cérebro que antecedem em muito esta recente formulação, que já pertence ao século XX -, o que nos lança em uma versão cerebralista do que Le Breton (1995, p. 55) chama de "imaginário de uma identidade singular dos órgãos". Um neurocientista convidado a participar de um debate sobre o individualismo pode justificar a sua presença com a afirmação de que “a cada cérebro corresponde um e um único indivíduo" (Percheron, 1987, p. 95). Essa mesma equivalência pode ainda ser explicitada em uma fórmula, o que confere à ideia uma aura de formulação lógica acerca da identidade pessoal: "uma pessoa P é idêntica a uma pessoa $\mathrm{P}^{*}$ se e somente se $\mathrm{P}$ e $\mathrm{P}^{*}$ são dotadas de um só e o mesmo cérebro funcional" (Ferret, 1993, p. 79).

Tal concepção de pessoa vem constantemente atravessando, em ambas as direções, a ponte através da qual se comunicam os discursos científico e leigo. Por um lado, é ao discurso científico que cabe (no sentido em que a ciência detém essa autoridade no Ocidente) produzir novas verdades sobre a 'natureza humana', hoje fortemente relacionada ao funcionamento do cérebro, assim como difundir tais ideias, que consistem em um modelo de pessoa, entre o público leigo. Por outro, há que se levar em conta que o público amplo não é 'estranho ao cérebro', no sentido em que não é recente a circulação de saberes sobre esse órgão, cuja centralidade em nosso corpo como um centro organizador já atravessa há muito uma cosmologia espontânea na cultura ocidental moderna.

A noção de que 'somos nosso cérebro' dá título a uma peça de teatro encenada na Argentina, ${ }^{2}$ baseada em textos de um psiquiatra, cujo primeiro diálogo coloca em cena a fórmula lógica aqui mencionada:

(O primeiro bloco de diálogo se passa em um consultório médico; as cenas são projetadas em uma tela atrás dos atores que já estão no palco.)

Hernán - Su hígado ya no funciona. Si lo reemplazamos por otro, usted podrá seguir viviendo. ¿Acepta?

Susana - Acepto.

Hernán - Su corazón no esta trabajando bien. Si lo reemplazamos por otro, usted podrá seguir viviendo. ¿Acepta?

Susana - Acepto.

Hernán - Su cerebro tiene dificultades. Si lo reemplazamos por otro, usted podrá seguir viviendo. ¿Acepta? 
Susana $-\ldots$

Hernán-¿Acepta?

(No palco, comentando a cena que se passou.)

Susana - Qué mal tenía el por ese dia.

Rosario - ¿Vos aceptarías?

Susana - ...hay días que sí.

Rosario - Yo no, no quiero dejar de ser yo justo ahora que me conozco un poco más (Bléfari \& Pampín, 2003).

Abrir mão de seu próprio cérebro, nesta cena de ficção, é abandonar a si mesmo, 'deixar de ser eu'. O órgão que se vai é a pessoa, que deixaria de ser ela mesma, enquanto o que se receberia é um outro indivíduo que passaria a ocupar aquele corpo. Nesse palco, a pessoa não é exatamente definida por um corpo indiviso, visto que, em contraste com o cérebro, o trânsito de alguns de seus órgãos é aceito sem maiores problemas; trata-se, sim, de um cérebro individual. Ao mesmo tempo que se divulga uma concepção cerebralista de pessoa, quando uma das personagens afirma que não gostaria de perder o seu cérebro 'justo agora que se conhece um pouco mais', algo aponta para uma 'interioridade psicológica' que se desvenda no decorrer do tempo através de um processo de autoconhecimento e mesmo para alguma noção de razão desprendida - afinal, que seria este yo que se conhece um pouco mais?

De alguma forma, a cena é bilíngue, no sentido em que conjuga a ideia do 'cérebro como pessoa' com uma noção de conhecimento de si que remete ao 'mental', como uma instância de outra ordem que o aparato biológico. Isso pode soar ambíguo em um primeiro momento; mas logo veremos que essa habilidade bilíngue é pretendida pelo discurso neurocientífico, que tem como objetivo ultrapassar os limites entre corpo e mente, sujeitando ambos a um monismo cerebral.

O cérebro tornou-se um personagem central para a nossa definição de identidade pessoal, de sujeito. Da neurociência à filosofia, da medicina à antropologia, especialistas têm se esmerado em comentar o lugar do cérebro hoje em relação ao corpo e à cultura, em discussões - diretas ou indiretas, já que nem sempre se trata de interlocutores - nas quais tensões são mais comuns do que concordâncias. Os debates apaixonados que se multiplicam sobre o seu funcionamento, funções e doenças são sinal desse lugar especial e controverso do cérebro. $\mathrm{O}$ adjetivo 'apaixonados' já avança aqui a ideia de que tais discursos não são ideologicamente neutros - e isso inclui, é claro, o meu próprio. Muito pelo contrário, ideias relacionadas ao cérebro estão em relação ou em tensão com questões de ordem política, religiosa e econômica. Para o cérebro, tido como o sítio biológico da mente e daquilo que nos define como indivíduos, vale especialmente o que Le Breton (1995, p. 56) afirma 
valer para todas as outras unidades distintas do corpo: “Não há inocência dos órgãos no imaginário ocidental, a parte vale pelo todo físico e moral."

Ao analisar discursos da ciência sobre o cérebro, temos um atalho particularmente rico para aceder à noção de 'pessoa' que faz parte de uma determinada visão de mundo. Como afirmaram Russo e Ponciano (2002, p. 349) a propósito deste tema, “examinar as novas teorias sobre a pessoa produzidas no âmbito da neurociência significa examinar uma nova forma de compreender/interpretar a pessoa que, ao mesmo tempo, indica novos modos de construção de si". Mas este é um ponto de vista antropológico. Um neurocientista poderia modificar a frase citada, invertendo a ideia de que possamos depreender uma noção de pessoa analisando os discursos da neurociência sobre o cérebro, e afirmando justamente que tal noção é um produto deste órgão, gerada e sustentada por ele, que caberia a uma ciência do cérebro desvendar:

Nos nossos dias, sabemos que é o nosso cérebro o que sustenta, gere e origina o nosso sentido de eu (self), de pessoalidade, o nosso sentido dos outros e a nossa humanidade. O cérebro é um órgão complexo, como o coração, os rins e o fígado. Mas quando pensamos nesses órgãos, não nos tornamos românticos ou nos preocupamos com eles como entidades encerradas em si próprias (Gazzaniga, 2005, p. 31).

Para Gazzaniga (2005) - em um bom exemplo da perspectiva da neurociência -, não se trata de um ramo científico que produz em seu discurso uma concepção de pessoa. É o cérebro quem produz e sustenta o que chamamos de personalidade e gera um sentido de self; no limite, este é o órgão que produz a nossa concepção de pessoa - a neurociência desvendaria, tão somente, os mecanismos por trás desse processo.

O cérebro tem um lugar peculiar em discursos contemporâneos sobre o corpo humano. Com status de sujeito, o cérebro tornou-se um órgão inevitável, incontornável, tema de debates que podemos chamar de 'científicomorais', fazendo um paralelo com a categoria 'físico-moral', como usado por Duarte (1986) para designar perturbações relacionadas a uma totalidade da pessoa, que tem consequências além da sua manifestação no corpo. Alguém já poderia dizer agora que qualquer tema relacionado ao corpo humano - sejam as suas doenças, seja o seu funcionamento considerado normal - é, em algum nível, físico-moral, assim como todo debate e todo fazer científicos seriam também 'guerra e discurso'. Mas digamos que algumas querelas científicas em torno do corpo humano são mais morais do que outras, expondo essa tensão de forma mais evidente. Vide não apenas aquelas que dizem respeito ao cérebro, mas também as discussões sobre células-tronco, aborto e manipulação genética, que trazem para a cena pública limites (ou o desmonte dos limites) entre vida e não-vida, natureza e cultura, herdado e adquirido. 
Em debates que dizem respeito ao cérebro, estão em jogo alguns dos valores centrais à cosmologia que atravessa a cultura ocidental moderna: autonomia, liberdade, razão, autenticidade e livre-arbítrio. Possivelmente seja esta a razão de que 'nos tornamos românticos' quando o assunto é o cérebro. Um órgão que ocupa posição hegemônica não é um órgão como outro qualquer; ele está em posição hierarquicamente superior a outros do corpo humano, à noção de mente - vista pela neurociência contemporânea como um epifenômeno do cérebro - e ao corpo ele mesmo, no sentido em que pode compor uma nova e peculiar versão dualista, na forma corpo/cérebro, que parece ocupar a diluída versão corpo/mente.

A ideia do 'cérebro como pessoa' é repetida em formatos variados em livros de divulgação de importantes neurocientistas, que visam atingir os seus pares especialistas, assim como constituir e ampliar o número de novos curiosos a respeito do funcionamento do cérebro. Não se trata de uma interpretação forçada, mas de uma ideia explícita. Para a neurocientista e psiquiatra Nancy Andreasen,

O cérebro é a essência daquilo que nos define como seres humanos. Compreender a sua estrutura e o seu funcionamento é compreender a nós mesmos. O cérebro saudável é um órgão complexo, milagroso e engenhosamente criado. Ele nos permite realizar as maravilhas da música, da arte, da ciência, da arquitetura, da engenharia, da organização política e da estrutura econômica. Cada um de nós foi dotado de um cérebro singular, com capacidades específicas que podemos aumentar pela aprendizagem e pelo trabalho produtivo ou desperdiçar pela inatividade intelectual e por hábitos de vida que não sejam saudáveis. Podemos usar nossos cérebros para finalidades boas, como construir pontes ou curar doenças, ou podemos usá-los para causar mal ou destruir os outros de muitas formas inovadoras (Andreasen, 2005, p. 43).

O modelo do indivíduo autônomo e singular é rebatido sobre o cérebro, que vira um agente que 'nos permite', no limite, construir um certo modelo de civilização. Assim, ainda que por um lado o discurso da neurociência esteja embasado sobre uma crítica ao dualismo cartesiano, uma das pedras de sustentação da noção de pessoa no Ocidente, por outro lado radicaliza algumas características do sujeito moderno, em especial os valores da singularidade, da autonomia e da possibilidade de constante construção de si (Russo e Ponciano, 2002). Outro modelo que salta aos olhos é o do progresso contínuo do sujeito, que pode melhorar o seu cérebro através dos 'bons hábitos' da 'aprendizagem' e do 'trabalho produtivo', em uma peculiar construção de si, algo como uma Bildung neurológica. ${ }^{3}$ Afinal, esses hábitos melhoram a nossa capacidade de realizá-los através de uma melhoria no próprio cérebro, que se mostra hoje aos olhos dos neurocientistas com acesso privilegiado a esse 
interior como um órgão plástico, cujas redes neuronais estão em constante modificação. O acesso à 'verdadeira natureza' do que 'nos define como seres humanos' dependeria, então, do conhecimento da estrutura e função cerebral.

Logo nas primeiras páginas de um de seus livros com perfil de divulgação científica, a neurocientista Susan Greenfield - que tem vários trabalhos de divulgação de neurociência para um público amplo, impressos e na TV - compara o cérebro, que seria um 'órgão pessoal', a outros órgãos do corpo humano, definidos como impessoais:

(...) a sua visão de mundo única e extremamente pessoal - a sua mente - dificilmente reside nas funções mecânicas do seu fígado, coração ou pulmões. Conforme avança a tecnologia médica, esses órgãos vitais, 'mas impessoais', serão transplantados com cada vez mais facilidade e frequência. Devo admitir a minha tendenciosidade, pois trabalho diariamente sobre a química do cérebro. Ainda assim, é o cérebro, afinal, que, ao ser bombardeado por drogas, assaltado por desordens psiquiátricas e neurológicas e vítima de ferimentos cranianos, está na raiz de quaisquer mudanças de caráter, nas emoções ou na consciência. Ali, por entre os liames de células invisíveis, impulsos elétricos e moléculas que vão do fantástico intrincado das proteínas à assombrosa simplicidade dos gases, ali onde o tempo se conta em menos de um milésimo de segundo, de alguma maneira é gestada uma experiência única e subjetiva em cada um de nós - uma experiência da consciência (Greenfield, 2000, p. 1, grifo nosso).

A baronesa Susan Greenfield é também a apresentadora de uma série de TV produzida pelo canal BBC, chamada Brain story, na qual ela aborda tópicos como religião, criatividade, memória e doenças neurológicas, sempre do ponto de vista de que o cérebro controla todas as nossas ações e emoções, definindo quem nós somos. Na introdução ao primeiro episódio, enquanto ela passeia por ruas de Jerusalém, em uma sequência entrecortada por imagens que mostram a diversidade religiosa que marca aquele local, fica ainda mais evidente qual a posição e quais as promessas da neurociência que são divulgadas contemporaneamente:

Na qualidade de neurocientista, a minha posição é a de que podemos explicar tudo sobre nós olhando lá dentro (looking inside). Estou certa de que tem de ser o cérebro a fazer de nós quem somos. As nossas esperanças, os nossos medos, pensamentos e sonhos estão de algum modo escondidos dentro das nossas cabeças. Estou convencida de que não há um único aspecto das nossas vidas que não resida na massa pastosa das nossas células nervosas. Estou convencida de que um dia seremos capazes de interpretar até mesmo os nossos sentimentos espirituais mais intensos em termos das operações (workings) do cérebro. A pesquisa está finalmente nos aproximando disso (Brain story, BBC, primeiro episódio). 
Apesar da 'certeza' demonstrada quanto ao papel que o cérebro exerce na definição de nossos medos, esperanças e pensamentos, e de estar 'convencida' de que nenhum aspecto do comportamento humano escapa ao controle da rede neuronal, essa introdução à série traz um tom de promessa futura, de uma boa nova ainda não atingida pelas possibilidades científicas atuais. Ainda assim, insinua-se uma noção de 'progresso' científico contínuo, já que as pesquisas estariam 'finalmente' se aproximando desse objetivo. Trata-se de uma estrutura discursiva que anuncia um possível futuro venturoso para as pesquisas que relacionam cérebro e subjetividade, em busca de correlatos neurais para sentimentos, emoções e mesmo para os 'mais intensos sentimentos espirituais'.

Para a neurociência contemporânea, o cérebro é visto como a "fronteira final" (Greenfield, 1997, p. 3) no que diz respeito ao entendimento do ser humano. Neste órgão estariam guardados os últimos mistérios da nossa "natureza'. Para de fato vencer essa suposta última fronteira, as ciências que se ocupam do cérebro, agregadas sobre o termo 'neurociência', teriam que ser bilíngues, segundo Susan Greenfield, para dar conta não somente da fisiologia de um órgão, mas também da mecânica capaz de gerar o fenômeno da memória, dos sentimentos, da aprendizagem e da consciência de si. Ela afirma:

Da forma como vejo, precisamos ser bilíngues. Com isso, quero dizer que devemos investigar tanto a neurociência - as operações físicas do cérebro - quanto os fenômenos subjetivos do sentimento. Precisamos nos familiarizar com as questões em torno do estudo dos eventos tanto físicos quanto epifenomenais do cérebro se de fato queremos compreender ambos (Greenfield, 2000, p. 2).

Ao estabelecer uma correlação direta entre os fenômenos físicos e epifenomenais que acontecem no cérebro, ou seja, reduzindo a esfera do 'mental' ou 'psicológico' a uma consequência física da rede neuronal, diluise aquilo que conhecemos como o dualismo mente/corpo, herança do pensamento cartesiano, em nome de uma perspectiva cerebralista da pessoa. Se nós somos o nosso cérebro, todas as capacidades humanas, para o bem e para o mal, estão relacionadas a esse órgão, e não a qualquer estrutura de caráter metafísico. A ideia de 'mente' mantém-se viva nessa perspectiva, mas como um subproduto do cérebro, uma consequência da rede neural em funcionamento. As duas palavras, então, podem ser usadas de forma intercambiável, o que possibilita que, em um mesmo livro de divulgação de saberes da neurociência e da psiquiatria, possam conviver duas ideias como as seguintes:

O cérebro humano é uma incrível obra de engenharia que nos permite processar bilhões de informações em um 'computador vivo' compacto, poderoso e continua- 
mente mutável, que carregamos sobre nossos ombros por toda a vida. Ele pesa pouco mais de um quilo, e cada um de nós recebe apenas um. Portanto, devemos entender os seus componentes, como ele funciona e como podemos cuidar bem dele - atualizando o seu software de maneira contínua e mantendo o seu sistema funcionando perfeitamente com o mínimo possível de problemas e incompatibilidades (Andreasen, 2005, p. 43).

As doenças mentais são uma condição que aflige as mentes, os cérebros e os espíritos de bilhões de pessoas em todo o mundo (Andreasen, 2005, p. VIII).

Pode surpreender e confundir, a um primeiro olhar, a convivência de um vocabulário radicalmente fisicalista, que fala em termos da informática, com outro que faz uso da ideia de 'mentes' e 'espíritos'. Ao mesmo tempo que a autora afirma que as doenças mentais "Afetam o cérebro e seu produto, a mente" (Andreasen, 2005, p. 17), ela pode inverter a ordem de causalidade e afirmar algumas páginas antes que "As doenças mentais são uma condição que aflige as mentes, os cérebros e os espíritos de bilhões de pessoas em todo o mundo" (Andreasen, 2005, p. VIII). Mas a pretensão bilíngue atual da neurociência pretende dar conta desse paradoxo ao equivaler os termos e ao mesmo tempo estabelecer entre eles uma hierarquia. Faz parte dessa pretensão a construção de uma 'moderna biologia do espírito', como afirma o neurocientista Jean-Pierre Changeux (1985) no prefácio ao seu livro $O$ homem neuronal.

O cérebro estaria, então, colado a (e seria determinante para) um determinado modelo de pessoa, uma categoria de análise antropológica que autores como Mauss (2003) e Dumont (2000) demonstraram ser situacional 'flutuante', afirma o primeiro; uma 'configuração ideológica', afirma o segundo, da qual o 'individualismo' seria apenas uma variação. Este modelo de pessoa ao qual me referi seria justamente aquele que, como afirma Duarte (2010) a propósito de suas reflexões sobre a categoria 'nervos' e o 'sistema nervoso', "se veio a conhecer como o 'indivíduo', uma totalidade indivisa, dotada de um 'sistema' interior articulador de todas as partes e dimensões de sua existência..." Este sistema interior parece ter-se deslocado da representação mais abrangente do 'sistema nervoso' como um todo para o cérebro em especial; mas continua valendo uma perspectiva 'totalizante', que Duarte definiu em trabalho recente como uma "qualidade de eixo ou centro articulador da pessoa humana desempenhado pelo sistema nervoso" (Duarte, 2010) e, antes, como uma

qualidade totalizadora básica que permite colocar o cérebro no ápice de uma hierarquia das funções internas dos organismos animais e o homem (com esse cérebro e esse sistema nervoso) no ápice de uma hierarquia evolutiva de organização 
e capacidade no quadro dos seres vivos. (...) o sistema nervoso é apresentado como o plano de mais alta articulação da pessoa, lugar de todos os fluxos necessários entre os centros de comando cerebrais e a periferia corporal, entre os órgãos de sentido e as redes sensoriais, garantindo a memória, a consciência, enfim todas as chamadas qualidades 'superiores'. Esse sistema é frequentemente apresentado nas obras gerais como homólogo ao dos 'aparelhos' em que se dividem as diversas funções vitais do organismo, embora hierarquicamente superior. Isso pressupõe a idéia de um órgão central, de uma rede de comunicação e de um fluxo qualquer entre o órgão e a rede. Quanto ao órgão central, não parece haver, há pelo menos um século, qualquer especulação que tenda a quebrar a hegemonia do cérebro... (...) Também quanto à rede, a representação de fibras, que se substitui no século XVIII à clássica imagem galênica dos tubos, tampouco parece contestável, embora complexificada com as modernas formulações neuronais (Duarte, 1986, p. 73-75, grifos do autor).

A ideia do cérebro como 'eixo' e 'órgão central' para o funcionamento do indivíduo não é, como já se pode divisar, nova. Mas essa antiga 'hegemonia do cérebro' pode ganhar novas roupagens sobre as quais vale a pena inquirir. Ainda que a hegemonia não seja nova, renovam-se o vocabulário, as representações e a tecnologia nos quais ela se baseia. O meu foco está voltado justamente para a difusão das 'modernas formulações neuronais', para o novo formato que o cérebro passa a ganhar em nosso tempo, cujas origens mais diretas remetem à virada do século XIX para o século XX; é nesse momento que o cérebro se torna mais molecular, com um novo vocabulário cujas estrelas centrais são os neurônios, sinapses e neurotransmissores. Na virada seguinte de século, tais palavras já fazem parte do acervo semântico do qual mesmo o público leigo lança mão em seu cotidiano. É nesse sentido que postulo aqui, como contribuição ao debate, a ideia de que um 'cerebralismo' (Azize, 2008, 2010) - uma concepção de pessoa que relaciona cérebro e indivíduo - constitui um traço central na concepção de pessoa moderna; trata-se de uma ideia que tem hoje ampla divulgação nos meios de comunicação, para a qual contribuem representações científicas e também leigas, e que conta com a autoridade da neurociência, por vezes deslizando para um tom normativo que flerta com a autoajuda. 


\section{Notas}

1 Doutor em Antropologia Social pelo Museu Nacional, Universidade Federal do Rio de Janeiro.<rogerioazize@hotmail.com>

Correspondência: Rua Antônio Vieira, n. 17, apto. 904, Leme, CEP 22010-100, Rio de Janeiro, RJ, Brasil.

2 Teve sua estreia em julho de 2003, no Centro Cultural Ricardo Rojas, em Buenos Aires, Argentina. A peça está baseada em textos do psiquiatra Sergio Strejilevich e faz parte de uma trilogia cujos próximos tópicos seriam a genética e a teoria do caos. A intenção é criar, assim se afirma em uma apresentação não assinada, "espetáculos de divulgação científica concebendo-o desde uma sensibilidade artística" (p. 13). O livro com o texto da peça foi-me presenteado pelo amigo Nicolas Viotti, a quem agradeço.

3 Ortega (2008) chama a atenção para o momento no qual Hans Castorp, o engenheiro que protagoniza o romance $A$ montanha mágica, de Thomas Mann, defronta-se pela primeira vez com uma imagem de raios $\mathrm{X}$ do seu próprio corpo. Castorp fica maravilhado e, ao mesmo tempo, mais consciente da sua mortalidade após visualizar parte de seu esqueleto. Ortega vai ressaltar a transformação pela qual passa o personagem após este episódio: "A partir deste momento ele deixa para trás a sua existência burguesa e dá início aos estudos científicos e filosóficos, transformando-se em um intelectual e cortando os laços com o mundo além dos confins do sanatório. Ele é invadido por uma vontade de saber sobre o corpo, que abarca desde o estudo da anatomofisiologia até o da metafísica, num processo que lembra o percurso descrito nos romances de formação (Bildungsroman) alemães, cujo modelo clássico é Os anos de aprendizagem de Wilhelm Meister, de Goethe. Para Castorp, a autoformação intelectual está ligada à descoberta e ao conhecimento do corpo, o que poderíamos denominar de somatização do ideal clássico da Bildung, de Bildung fisiológica. O conhecimento do interior do corpo representa uma metáfora eficaz do conhecimento de si" (Ortega, 2008, p. 128-129).

\section{Referências}

ANDREASEN, Nancy. Admirável cérebro novo: vencendo a doença mental na era do genoma. Porto Alegre: Artmed, 2005.

AZIZE, Rogerio Lopes. Uma Neuro-Weltanschauung? Fisicalismo e subjetividade na divulgação de doenças e medicamentos do cérebro. Mana: Estudos de Antropologia Social, Rio de Janeiro, v. 14, p. 7-30, 2008.

A nova ordem cerebral: a concepção de 'pessoa' na difusão neurocientífica.
Tese (Doutorado em Antropologia Social) Museu Nacional/UFRJ, Rio de Janeiro, 2010.

BLÉFARI, Rosario; PAMPÍN, Susana. Somos nuestro cérebro: ensayo de divulgación científica (peça de teatro sobre textos de Sergio Strejilevich). Buenos Aires: Libros del Rojas/Universidad de Buenos Aires, 2003.

CHANGEUX, Jean Pierre. O homem neuronal. Lisboa: Publicações Dom Quixote, 1985. 
DUARTE, Luiz Fernando D. Da vida nervosa nas classes trabalhadoras urbanas. Rio de Janeiro: Zahar, 1986.

O nervosismo como categoria nosográfica no começo do século XX. Artigo no prelo, 2010.

DUMONT, Louis. O individualismo: uma perspectiva antropológica da ideologia moderna. Rio de Janeiro: Rocco, 2000.

FERRET, Stephane. Le philosophe et son scalpel: le problème de l'identité personnelle. Paris: Minuit, 1993.

GAZZANIGA, Michael S. The ethical brain. New York: Dana Press, 2005.

GREENFIELD, Susan. The human brain: a guided tour. London: Weidenfeld and Nicolson, 1997.

The private life of the brain: emotions, consciousness, and the secret of the self. New York: John Wiley and Sons, 2000.
LE BRETON, David. A síndrome de Frankenstein. In: SANT'ANNA, Denise Bernuzzi de. (Org.) Políticas do corpo. São Paulo: Estação Liberdade, 1995. p. 49-67.

MAUSS, Marcel. Uma categoria do espírito humano: a noção de pessoa, a noção do 'eu'. In: Sociologia e antropologia. São Paulo: Cosac \& Naify, 2003. p. 367-397.

ORTEGA, Francisco. O corpo incerto: corporeidade, tecnologias médicas e cultura contemporânea. Rio de Janeiro: Garamond, 2008.

PERCHERON, Gérard. Neuromythologies: cerveau, individu, espèce et société. In: VEYNE, Paul et al. Sur l'Individu (coletânea de intervenções apresentadas no colóquio 'Sur l'Individu', 22-24 out. 1985). Paris: Éditions de Seuil, 1987.

RUSSO, Jane A.; PONCIANO, Edna T. O sujeito da neurociência: da naturalização do homem ao reencantamento do mundo. Physis: Revista de Saúde Coletiva, Rio de Janeiro, v. 12, n. 2, p. 345-373, 2002. 